\title{
The Effect of Quercus infectoria Acorn on Clinical, Hematobiochemical Parameters of Pregnant Albino Rats
}

\begin{abstract}
Background: Quercus infectoria is a kind of forest tree widely used for livestock feeding within the northern parts of Iraq with little was known about the Quercus infectoria toxicity mainly in pregnant animals. Therefore, this study aimed to investigate the potential effect of Quercus infectoria acorn on the pregnant albino rats.

Methods: This study was conducted on the Wistar pregnant rats, using aqueous extract of the acorn at doses of $2 \mathrm{grams} / \mathrm{rat}$ for a period of 10 days. The effect of the quercus acorn on the animal behavior, pregnancy hematobiochemical parameters was investigated compared to the control groups.

Result: Neither mortality, nor significant changes in animals' behavior were detected in treated rats; whereas, abortion and early parturition with lower weight of the pups were observed in treated pregnant rats. Significant increases in red blood cells, packed cell volume, hemoglobin concentration, means corpuscular volume and means corpuscular hemoglobin and levels of neutrophils and eosinophil were reported in treated rats compared to the control groups. Besides, blood urea nitrogen and aspartate aminotransferase were significantly increased in the treated group. Study results suggest that the aqueous extract of Quercus infectoria acorn has potential toxic effects on pregnancy.

Key words: Abortion, Blood parameters, Poisoning, Quercus infectoria acorn.
\end{abstract}

\section{INTRODUCTION}

Quercus infectoria is a species of oak bearing galls, oak and acorn that have been widely used for medical purposes (Mahboubi, 2020) and as nutritive sources for ruminants (Motamedi et al., 2019). The plant is a forest tree and indigenous to the many countries of north hemosphire including Iraq (Mahboubi, 2020). The main chemical components of the fruity structures of the tree are tannins, gallic acid and ellagic acid which are the main characteristic for their medicinal properties (Al-Rousan et al., 2013). Besides, the quercus found to contain various electrolyte including Phosphorous (21.40 to 80.80), Sodium (141.17 to 278.17) $\mathrm{mg} / 100 \mathrm{~g}$ of dry weight (Rababah et al., 2010) and Potassium contents of Quercus infectoria at 1222.50 , Calcium 40.00 and Chlorine 54.00 ( $\mu \mathrm{g} / \mathrm{g}$; dry weight basis) (Ajo et al., 2020).

Phenolic compounds of the acorn induce various effects, where tannic acid found to modulate immune responses in favor of sheep in response to parasitic infestation (Zhong et al., 2014) and stimulate immune response through increasing polymorphonuclear leukocytes (Burlacu, Nisca and Tanase, 2020). Tannic and gallic acid also found to induce erythropiosis through increasing nuclear contents of transcription factors in body cells and chelating free radicals such as iron (Phiwchai et al., 2018). Whereas, tannic component of the quercus found to induce toxic effect in kidney where it causes tubular cell necrosis and nephrosis in ruminant, lamb and calves (Eroksuz et al., 2013). Gallic acid, tannin and ellagic acid found to interfere with the serum level of sex hormones in treated rats (Mazloom et al., 2019) and induce spontaneous contractile uterine muscle in human
1Department of Veterinary Medicine and Surgery, College of Veterinary Medicine, University of Duhok, Duhok, Iraq.

${ }^{2}$ Department of Planning and Following up in Duhok Veterinary Directorate/Ministry of Agriculture and Water resource/ Kurdistan Region/ Iraq.

Corresponding Author: Nawzat Aboziad Issa, Department of Veterinary Medicine and Surgery, College of Veterinary Medicine, University of Duhok, Duhok, Iraq. Email: nawzat.issa@uod.ac

How to cite this article: Issa, N.A., Ali, B.A. and Saed, S.T. (2022). The Effect of Quercus infectoria Acorn on Clinical, Hematobiochemical Parameters of Pregnant Albino Rats. Indian Journal of Animal Research. DOI: 10.18805/IJAR.BF-1451.

Submitted: 06-10-2021 Accepted: 09-12-2021 Online: 06-01-2022

through muscarinic receptor system (Amiera et al., 2014).

Local farmers increasingly claimed in term of the increases in abortion rates among their livestock, sheep and goats following consumption. Accordingly, the present study was conducted using pregnant albino rats as a model to evaluate the impact of a corn compounds on pregnancy and to give insights to the local animal owners, veterinarian and stockholders toward the potential effect of the quercus on the animal pregnancy.

\section{MATERIALS AND METHODS}

Preparation of aqueous extract of acorn of Quercus infectoria

This study was conducted from October 2018-June 2019, at college of Veterinary Medicine, University of Duhok, Iraq. 
The Quercus infectoria Acorns (QIA) used in this study were collected from Khrabia Village mountains' located in Duhok province, Iraq. For authentication, the collected acorns were sent to a taxonomist in College of Agricultural Engineering Sciences-University of Duhok. The verified collected acorns were cleaned with tap water, air-dried indoors; grounded by electrical grinder into fine powder. The obtained powders were sieved using analytical sieve $(710 \mu$,$) to remove coarse$ particles and then soaked in deionized water at a volume ratio of 1:4 (W/V) for $48 \mathrm{hrs}$. The obtained stock suspensions were filtered before use; the filtered suspensions were orally given to pregnant rats for a period of 10 days. Each rat daily received 2 gram ( $8 \mathrm{ml} /$ animal), the chosen dose was according to a study recorded that $L_{50}$ was greater than 10 $\mathrm{gm} / \mathrm{kg}$ (Iminjan et al., 2014).

\section{Experimental animals}

30 pathogen free adult females Wistar rats (3-4 months), weighing $225-250 \mathrm{~g}$ were used in this study to detect the toxic effects of the QIA on pregnant rats compared to controls groups of non-treated pregnant rats and non-treated nonpregnant rats. The used rats were kept in the animal house at the College of Veterinary Medicine-University of Duhok. The used rats were caged 5 rats/cage. For breeding purposes, the polygamous mating system was adopted in this study, where 3 females/ 1 male were kept in cages for a period of three successive days; the females were daily checked for the presence of the vaginal plague as an indicator for the occurred sexual activities. The presence of the vaginal plague was considered as first date of pregnancy. To confirm the pregnancy, the palpation of lower abdominal part and changes in hair around nipples and in the nipples sizes were later daily observed. The pregnant rats were separated from males and kept at 3 rats per cage. During this study, all the used rats were kept in a room with wellcontrolled temperature at $22-25^{\circ} \mathrm{C}$ and exposed to $12 \mathrm{~h}$ dark $112 \mathrm{~h}$ light cycle. The used rats were fed on standard rats' pellet diet. This study was firstly approved by Animal Ethical Committee at the College of Veterinary Medicine, University of Duhok, Iraq. (Permit number: DR20210218C /2019/02/04).

\section{Experimental design}

To investigate the potential effect of QIA on clinical and some of hematological and biochemical parameters in lab animal, 30 adult female (20 pregnant, 10 non-pregnant) albino rats were used in this study. The used rats were grouped into 3 groups (group A, B and C), 10 rats/group. Rats in group B and $C$ were controls. The pregnant rats were randomly distributed between group $A$ and $B$, where group $A$ was pregnant-QIA treated rats, group $B$ pregnant but not-treated control and group $C$ non pregnant- non-treated control. The used rats were kept in standard plastic cages, 3 rats/ cage.

\section{Clinical signs assessment}

To detect the effect of QIA on the clinical signs of the used rats as animal behavior including (posture of animal, respiration, animal hairs, appetite, defecation, urination, restlessness and vocalization), mortality, abortion, early parturition, weight of pups) were daily observed in treated and non-treated rats during the whole experiment period of 25 days.

\section{Hematobiochemical parameters}

Blood samples were collected following the orbital venous plexus bleeding procedure according to (Parasuraman, Raveendran and Kesavan, 2010). Blood samples were collected from treated rats after 10 days post treatment and control groups (pregnant non-treated rats after 10 days of pregnancy confirmation and non-pregnant non-treated rats). The blood samples were collected into heparinized tube and plain tube at $1 \mathrm{ml} / \mathrm{tube}$. The obtained blood samples were immediately delivered in cold box to the lab of the Clinical Pathology at the College of Veterinary Medicine, University of Duhok, Iraq for hematological parameters assessment and sera separation to be used later for biochemical parameters.

Hematology (Hemoglobin $(\mathrm{Hb})$ concentration, packed cell volume (PCV), white blood cells (WBCs) and red blood cells (RBCs) of the samples were performed as descried by (Nadeem et al., 2021) and differential leucocytic counts (DLC) by using Giemsa-stained blood smear technique (Gupte, 2009). Mean corpuscular volume (MCV), mean corpuscular hemoglobin $(\mathrm{MCH})$ and mean corpuscular hemoglobin concentration ( $\mathrm{MCHC}$ ) were calculated as stated by (Ajakaiye et al., 2010).

Blood urea nitrogen (BUN), Creatinine, aspartate aminotransferase (AST), alanine aminotransferase (ALT), alkaline phosphatase (ALP), Phosphorous, Calcium, Sodium, Potassium and Chloride were determined by KENZA 240 TX chemical auto analyzer (Bio Lab. France) according to the manufacturer's instructions.

\section{Statistical analyses}

Statistical analysis was performed using One-way ANOVA and t-tests using GraphPad Prism 8.0.1 software to compare between treated and non-treated pregnant groups. Significant means $(P<0.05)$, data are presented as the means \pm SEM.

\section{RESULTS AND DISCUSSION}

In this study, comparisons between the studied parameters were made between the non-pregnant non-treated rats and pregnant-non treated rats firstly to see any potential differences within the parameters in control groups. No significant difference was found between the parameters in these two groups.

In QIA treated groups, neither mortality, nor significant changes in animals' behavior were detected compared to the controls (Table 1). The signs of the acute toxicity of QIA with regards to respiration, animal fur, appetite, defecation, urination, restlessness and vocalization were normal. These finding are in line with that reported in mice, rats and rabbits even those treated with maximum tolerance dose of Quercus infectoria galls at $10 \mathrm{~g} / \mathrm{kg}$ (Iminjan et al., 2014).

The effect of QIA in pregnant treated rats found to be significant, where abortion was reported in one of treated 
The Effect of Quercus infectoria Acorn on Clinical, Hematobiochemical Parameters of Pregnant Albino Rats

Table 1: Effect of QIA on the clinical signs on experimental rats.

\begin{tabular}{lccc}
\hline Parameters & Control- non pregnant non-treated group & Non- treated pregnant rats & Treated pregnant rats \\
\hline Behavior & - & - & - \\
Mortality & - & $0 / 10$ & $0 / 10$ \\
Early parturition & - & $0 / 10$ & $6 / 9$ \\
Abortion & - & $0 / 10$ & $1 / 10$ \\
\hline
\end{tabular}

rats and early parturition was reported in 6 out of the 9 treated rats, on average, three days earlier than that of control (pregnant non-treated group). The weight of the pups of QIA treated rats at birth were significantly $(p<0.01)$ lower than that of control pups (Fig 1). The reproductive effects could be due to increases within the contractile uterine smooth muscle in response to the Quercus infectoria components (Noureddini et al., 2018). Gallic acid found to increase the serum level of $\mathrm{LH}$, estradiol and testosterone and reduce the serum level of $\mathrm{FSH}$ and progesterone in experimentally treated Wistar female rats (Mazloom, Edalatmanesh and Hosseini, 2019). Besides, Tannin and Ellagic acid found to induce spontaneous contractile response within the human uterine muscle through muscarinic receptor system (Amiera et al., 2014).

The effect of QIA on blood parameters in treated rats was detected and the data are presented in (Table 2). Significant increases $(p<0.05)$ were observed in RBC, PCV and $\mathrm{Hb}$ in QIA treated rats compared to control group. However, the means corpuscular volume and means corpuscular hemoglobin of rats treated with the QIA showed significant $(P<0.05)$ decreases compared to the control. Quercus infectoria induce increases in erythrocytic parameters in laboratory animals, is not explainable. Besides, ingredients with erothropiotic activity were found within the QIA that increased nuclear contents of transcription factors in all body cells including RBC (Sharma et al., 2010). Further, Bohlouli et al., (2016) reported increases in haematological parameters in rainbow trout treated with Persian oak (Quercus brantii var. persica) fruit extract and suggested that active ingredients in Persian oak fruit extract have stimulatory roles on the level of many cells in the body including RBC. Whereas, MCV and MCH of QIA treated rats showed significant decreases which could be due to the effect of the tannic acid which causes cell shrinkage and cell membrane scrambling with appearance of phosphatidylserine at the erythrocyte surface in process known eryptosis (Abed et al., 2013). Tannic acid and Gallic acid are iron chelator and are capable of binding and scavenging free radicals such as iron (Phiwchai et al., 2018).

The differential leucocytic counts of the white blood cell expressed in absolute values are presented in (Fig 2). The data showed significant $(P<0.05)$ increases in levels of neutrophils and eosinophil in the QIA treated rats compared to the control. These findings are in line with that reported in female rats treated with Quercus Infectoria Galls water extract (Iminjan et al., 2014) and in rainbow trout, Oncorhynchus mykiss treated with Persian oak (Quercus brantii var. persica) (Bohlouli et al., 2016). Ugur Calis et al.,
Table 2: Effect of QIA on hematological parameters in treated rats after 10 days of treatment compared to the control, pregnant- non-treated female rats.

\begin{tabular}{lcc}
\hline Parameters & $\begin{array}{c}\text { Control/ pregnant } \\
\text { non-treated group }\end{array}$ & $\begin{array}{r}\text { pregnant QIA- } \\
\text { treated group }\end{array}$ \\
\hline RBC $\left(\mathrm{X} 10^{6} / \mathrm{ml}\right.$ & $4.86 \pm 0.05$ & $11.53 \pm 0.43^{* * *}$ \\
$\mathrm{PCV}(\%)$ & $31.33 \pm 0.88$ & $42.33 \pm 2.02^{* *}$ \\
$\mathrm{Hb}(\mathrm{g} / \mathrm{dl})$ & $11.93 \pm 0.07$ & $14.33 \pm^{*}$ \\
$\mathrm{WBC}\left(10^{3} / \mathrm{ml}\right)$ & $15.9 \pm 0.1$ & $18 \pm 2.6$ \\
$\mathrm{MCV}(\mathrm{fl})$ & $64.57 \pm 2.12^{* *}$ & $36.7 \pm 0.61$ \\
$\mathrm{MCH}(\mathrm{Pg})$ & $24.57 \pm 0.43^{* *}$ & $12.47 \pm 0.92$ \\
$\mathrm{MCHC}(\mathrm{Pg})$ & $38.14 \pm 1.05$ & $33.95 \pm 2.23$ \\
\hline
\end{tabular}

Table 3: Effect of QIA on values of the blood measured electrolytes in treated rats after 10 days of treatment compared to the control pregnant- non-treated female rats.

\begin{tabular}{lcc}
\hline Parameters & $\begin{array}{c}\text { Control pregnant } \\
\text { non-treated group }\end{array}$ & $\begin{array}{c}\text { Pregnant QIA- } \\
\text { treated group }\end{array}$ \\
\hline Phosphorous mg/dL & $4.90 \pm 0.27$ & $5.39 \pm 0.15$ \\
Calcium mg/dL & $10.03 \pm 0.3$ & $10.43 \pm 0.2$ \\
Sodium $\mathrm{mEq} / \mathrm{L}$ & $142.67 \pm 1.45$ & $146.00 \pm 2.89$ \\
Potassium mEq/L & $4.34 \pm 0.39$ & $4.69 \pm 0.4$ \\
Chloride $\mathrm{mEq} / \mathrm{L}$ & $107.33 \pm 0.88$ & $109.33 \pm 2.9$ \\
\hline
\end{tabular}

The data are presented as Mean+SE of triplicates per each/sample.

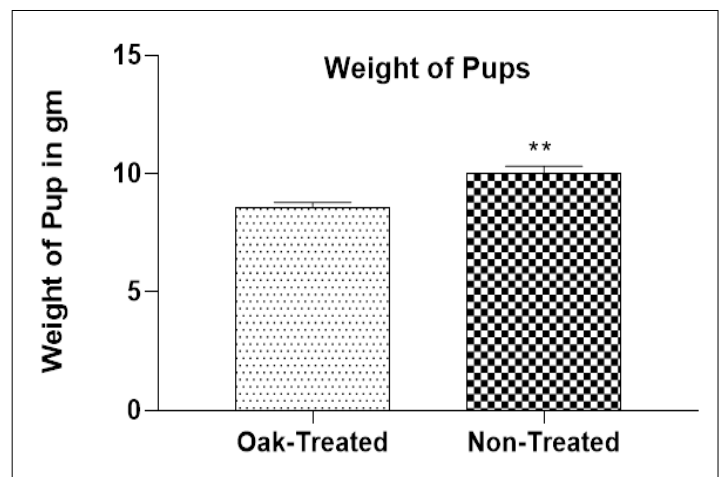

Fig 1: The weight of the pups of QIA treated rats compared to non-treated rats at birth.

(2016) also reported increases in number of neutrophils in females' rats in response to tannic acid treatment; the increases is probably due to the immune-stimulator role of the components of the quercus genus (Bohlouli et al., 2016; Burlacu et al., 2020). The eosinophilia in treated rats is probably due to the effect of the tannic acid (Zhong et al., 2014).

The effect of QIA on some of the biochemical parameters (Fig 3 ) in treated rats was also detected and compared to the control group; the analyzed data showed 


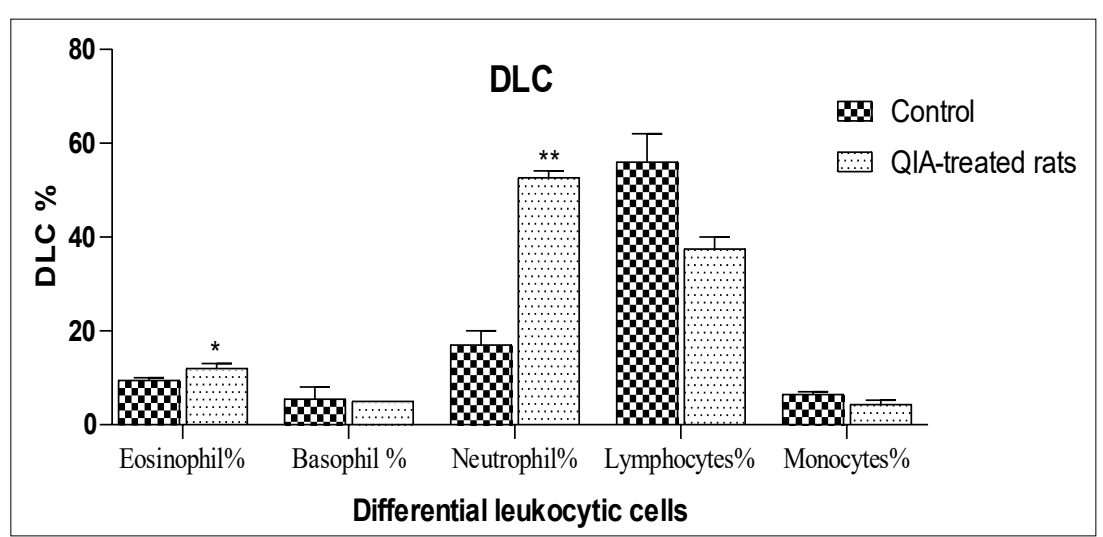

Fig 2: Effect of QIA on differential leukocytic counts in treated pregnant rats compared to control groups.

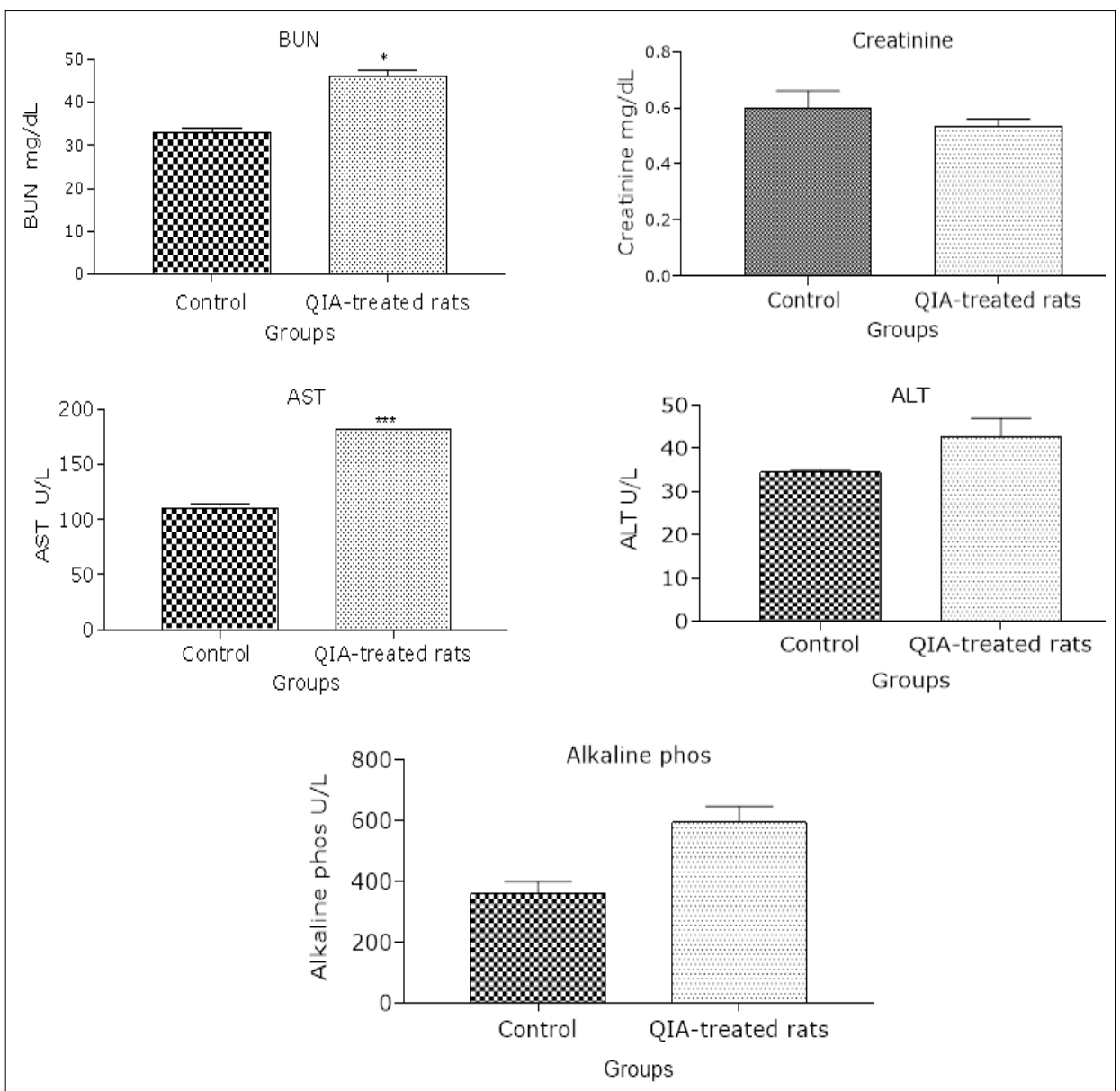

Fig 3: Biochemical parameters in pregnant female treated with QIA compared to the controls groups

significant differences $(P<0.05)$ in BUN and AST between the treated rats and the control. The increases in level of serum BUN and AST in treated rats are probably due to the toxic effects of the quercus components on the kidney, liver and others body tissues(Huang et al., 2006). Histopathological changes were reported in kidneys of lambs fed with Quercus infectoria; the changes were multifocal tubular cell necrosis, multifocal moderate cell swelling, multifocal tubular dilatation and hyaline cast formations plus increases in blood urea nitrogen levels (Eroksuz et al., 2013). Elevations in Alanine transaminase (ALT) and Alkaline phosphatase (ALP) also were reported in female rats treated with Quercus infectoria extract in water (Iminjan et al., 2014).

Whereas, the values of the blood measured electrolytes (Table 3) during this experiment were within their normal ranges. These finding are in line with that reported in quercus 
infectoria components treated rats (Iminjan et al., 2014); where, it has been reported that acorn of quercus contain phosphorous, sodium, potassium, calcium and chlorine which probably maintain the serum level of the electrolytes (Rababah et al., 2010; Ajo et al., 2020).

\section{CONCLUSION}

Taken together, the negative impacts of the quercus infectoria acorn on the treated rats were ranged from abortion and induced early parturition to significant changes in hematobiochemical parameters. Further comprehensive studies are needed to fully understand the effect of the quercus on the animal reproduction and the associated mechanisms.

\section{REFERENCES}

Abed M., Herrmann T., Alzoubi K., Pakladok T., Lang F. (2013). Tannic acid induced suicidal erythrocyte death. Cellular Physiology and Biochemistry. 32: 1106-1116. DOI: 10.11 59/000354510.

Ajakaiye, J.J., Pérez-Bello, A., Cuesta-Mazorra, M., García-Díaz, J.R., Mollineda-Trujillo, Á. (2010). Effects of vitamin C and E dietary supplementation on erythrocyte parameters of layer chickens reared in high ambient temperature and humidity. Revista Brasileira de Ciencia Avicola. 12: 205209. DOI: $10.1590 / S 1516-635 X 2010000300010$.

Ajo, R.Y., Al-Rousan, W.M., Rababah, T., Maghaydah, S., Angor, M.M. (2020). Physiochemical properties and nutritional profile of Mediterranean Oak acorn. African Journal of Food, Agriculture, Nutrition and Development. 20: 16371-16385. DOI: 10.18697/AJFAND.93.19170.

Al-Rousan, W.M., Ajoa, R.Y., Al-Ismailb,K.M., Attleec, A., Shakerdand, R.R., Osaili T.M. (2013). Characterization of acorn fruit oils extracted from selected mediterranean quercus species. Grasas y Aceites. 64: 554-560. DOI: 10.3989/ gya. 023313.

Amiera, Z. et al. (2014). Phytochemical characteristic and uterotonic effect of aqueous extract of Ficus ditoidea leaves in Rats uterus. Pakistan Journal of Biological Sciences. 17: 10461051. DOI: $10.3923 /$ pjbs.2014.1046.1051.

Bohlouli, S., Ghaedi,G., Heydari,M., Rahmani,A., Sadeghi, E. (2016). Effects of dietary Persian oak (Quercus brantii var. persica) fruit extract on survival, growth performance, haematological and immunological parameters in rainbow trout, Oncorhynchus mykiss, fingerlings. Aquaculture Nutrition. 22: 745-751. DOI: 10.1111/anu.12290

Burlacu, E., Nisca, A. and Tanase, C. (2020). A comprehensive review of phytochemistry and biological activities of Quercus species. Forests. 11:904. DOI: 10.3390/F11090904

Eroksuz Y, Dabak M, Eroksuz H, Baudar E, Turkoglu I, Yilmaz I. (2013). Acute oak (Quercus infectoria) toxicosis in lambs. Revue de Medecine Veterinaire (Toulouse).164: 302-306.

Gupte, S. (2009). The Short Textbook of Pediatrics (1 $11^{\text {th }}$ Edition). DOI: $10.5005 /$ jp/books $/ 10983$.

Huang, X.J., Choi, Y.K., Im, H.S., Yarimaga, O., Yoon, E., Kim, H.S. (2006). Aspartate aminotransferase (AST/GOT) and alanine aminotransferase (ALT/GPT) detection techniques. Sensors. 6: 756-782. DOI: $10.3390 / \mathrm{s} 6070756$.

Iminjan, M., Amat, N., Li, X.H., Upur, H., Ahmat, D., He, B. (2014). Investigation into the toxicity of traditional uyghur medicine quercus infectoria galls water extract. PLoS One. 9: 1-8. DOI: 10.1371/journal.pone.0090756

Mahboubi, M. (2020). Quercus infectoria fruit hulls and galls and female genital disorders. Clinical Phytoscience. DOI: 10.1186/s40816-020-00194-9.

Mazloom, B.F., Edalatmanesh, M.A. and Hosseini, S.E. (2019). Gallic acid reduces inflammatory cytokines and markers of oxidative damage in a rat model of estradiol-induced polycystic ovary. Comparative Clinical Pathology. 28: 1281-1286. DOI: 10.1007/s00580-019-02920-3

Motamedi, H., Azizi, A. and Ahmadi, M. (2019). Nutritive value of treated Quercus infectoria and Quercus libani leaves with the tannin-degrading bacterium Klebsiella pneumoniae for ruminant feeding in vitro. Journal of Applied Microbiology. 127: 1339-1348. DOI: 10.1111/jam.14408.

Nadeem, S.M., Khan, M.ur.R., Aslam, A., Sheikh, A.A., Ahmad, A., Latif, A.A. and Anjum, A. (2021). Clinicopathological and hemato-biochemical assessment of field originated chicken anemia virus in experimentally challenged broiler chicken. Indian Journal of Animal Research. 55(8): 936940. DOI: 10.18805/ijar.B-1229.

Noureddini, M., Nadali M., Banafshe HR. (2018). Effect of aqueous extract of Quercus Infectoria gall on the basic contractility, frequency and strength of isolated virgin rat uterus smooth muscle. Health Biotechnology and Biopharma. 1: $56-65$.

Parasuraman, S., Raveendran, R. and Kesavan, R. (2010). Blood sample collection in small laboratory animals. Journal of Pharmacology and Pharmacotherapeutics. 1: 87-93. DOI: 10.4103/0976-500X.72350.

Phiwchai, I., Yuensook, W., Sawaengsiriphon, N., Krungchanuchat, S., Pilapong, C. (2018). Tannic acid (TA): A molecular tool for chelating and imaging labile iron. European Journal of Pharmaceutical Sciences. 114: 64-73. DOI: 10.1016/ j.ejps.2017.12.004

Rababah, T., Ereifej, K., Al-mahasneh, M., Alhamad, M.N. (2010). The physicochemical composition of acorns for two mediterranean quercus species. Jordan Journal of Agricultural Sciences. 4:131-137.

Sharma, A., Deo, A.D., Tandel Riteshkumar, S., Chanu, T.I., Das, A. (2010). Effect of [Withania somnifera (L.) Dunal] root as a feed additive on immunological parameters and disease resistance to Aeromonas hydrophila in Labeo rohita (Hamilton) fingerlings. Fish and Shellfish Immunology. 29: 508-512. DOI: 10.1016/j.fsi.2010.05.005.

Ugur Calis, I., Turgut Cosan, D., Saydam, F., Kerem Kolac, U., Soyocak, A., Kurt, H., et al. (2016). The effects of monosodium glutamate and tannic acid on adult rats. Iranian Red Crescent Medical Journal. 18: e37912. DOI: 10.5812/ ircmj.37912.

Zhong, R.Z., Sun, H.X., Liu, H.W., Zhou, DW. (2014). Effects of tannic acid on Haemonchus contortus larvae viability and immune responses of sheep white blood cells in vitro. Parasite Immunology. 36: 100-106. DOI: 10.1111/pim.12092. 